\title{
UNA MIRADA ANTROPOLÓGICA AL DEVENIR MINERO DE TALTAL Y PAPOSO ${ }^{1}$
}

\author{
AN ANTHROPOLOGICAL VIEW OF THE HISTORICAL MINING \\ PROCESS OF TALTAL AND PAPOSO
}

\author{
Victoria Castro $^{1}$, Manuel Escobar ${ }^{2}$ y Diego Salazar ${ }^{3}$
}

\begin{abstract}
Presentamos los resultados de un estudio realizado sobre diversas clases de documentos, con el fin de dar a conocer la relación entre la minería y el devenir histórico-social del área de Taltal-Paposo en la costa desértica del norte grande de Chile, desde la prehistoria a nuestros días. Para su documentación, se trabajó en el Archivo Nacional de Chile, se recurrió a impresos de los siglos XIX, XX y XXI y se analizó material arqueológico y etnográfico que se ha obtenido en la localidad, a fin de mostrar las continuidades y cambios socioculturales producto del desarrollo minero en este territorio. Se ofrece este aporte desde un enfoque antropológico, que pretende un diálogo amplio transdisciplinar.
\end{abstract}

Palabras claves: Taltal, Paposo, antropología histórica, minería, continuidades y transformaciones.

In this paper we present results from an interdisciplinary study of a diverse array of documents centered on the mining history of the Taltal-Paposo area and its relation to the social process in this part of the desert coast of northern Chile. We focus on an anthropological-historical perspective spanning from prehistory until the present day. We use historical data from the Archivo Nacional de Chile, printed materials from $19^{\text {th }}, 20^{\text {th }}$ and $21^{\text {st }}$ centuries, and archaeological and ethnographic data. We attempt to show continuities and sociocultural changes caused by the historical mining process of these localities from an anthropological point of view based on a cross-disciplinary dialogue.

Key words: Taltal, Paposo, historical anthropology, mining, continuities and transformations.

La presencia europea en América significó un giro respecto de la búsqueda y explotación de minerales, constituyéndose en una de las principales actividades económicas en el territorio de los Andes del Sur (Cruz y Vacher 2008; Weaver 2008; entre otros). El metal llegó a ser "un recurso altamente redituable en términos económicos, además de una metáfora de riqueza, acceso al poder y acrecentamiento del estatus social" (Gluzman 2007:176). En este contexto de profundos cambios que significó la minería en el devenir social, ofrecemos imágenes de continuidades y transformaciones en dos localidades mineras de la costa norte de Chile -Taltal y Paposo- que denotan diversos acercamientos en la construcción del conocimiento asociado a la dimensión histórica de la minería.

Hoy en día la aproximación a la vida social en culturas diversas requiere múltiples esfuerzos transdiciplinarios para comprender al ser humano. Así por ejemplo, la colaboración entre historia y antropología es amplia y posible, respetando cada metodología disciplinaria, flexibilizando fronteras sin perder identidad. En este escrito nos interesa otorgarle sentido a informaciones de diversa procedencia, con el fin de contribuir al conocimiento y comprensión de un segmento social en el tiempo y un espacio acotado, logrando una visión lo más holística posible aunque no exhaustiva. Para ello requerimos de los aportes de las ciencias sociales, las humanidades y hasta las artes. En este contexto, consideramos diferentes tipos de fuentes y en consecuencia tenemos que apelar al trabajo documental en todas sus formas como los aportes desde la arqueología, narrativas orales y escritas, documentación gráfica y otras. Es una mirada desde la antropología, que en el caso de estudio y en el presente podría contenerse en lo que se concibe como antropología histórica, término usual en la actualidad (Boccara 2002).

En el marco de dos proyectos FONDECYT en las localidades de Taltal y Paposo (2008-2011, Figura 1), hemos buscado información de distintas

\footnotetext{
Centro de Investigaciones del Hombre en el Desierto (CIHDE), Universidad de Tarapacá, Arica, Chile. vcastror53@gmail.com Miguel Claro 070, Depto. 805, Providencia, Santiago, Chile. mem1074@ gmail.com

Departamento de Antropología, Facultad de Ciencias Sociales, Universidad de Chile, Santiago, Chile.dsalazar@uchile.cl
} 


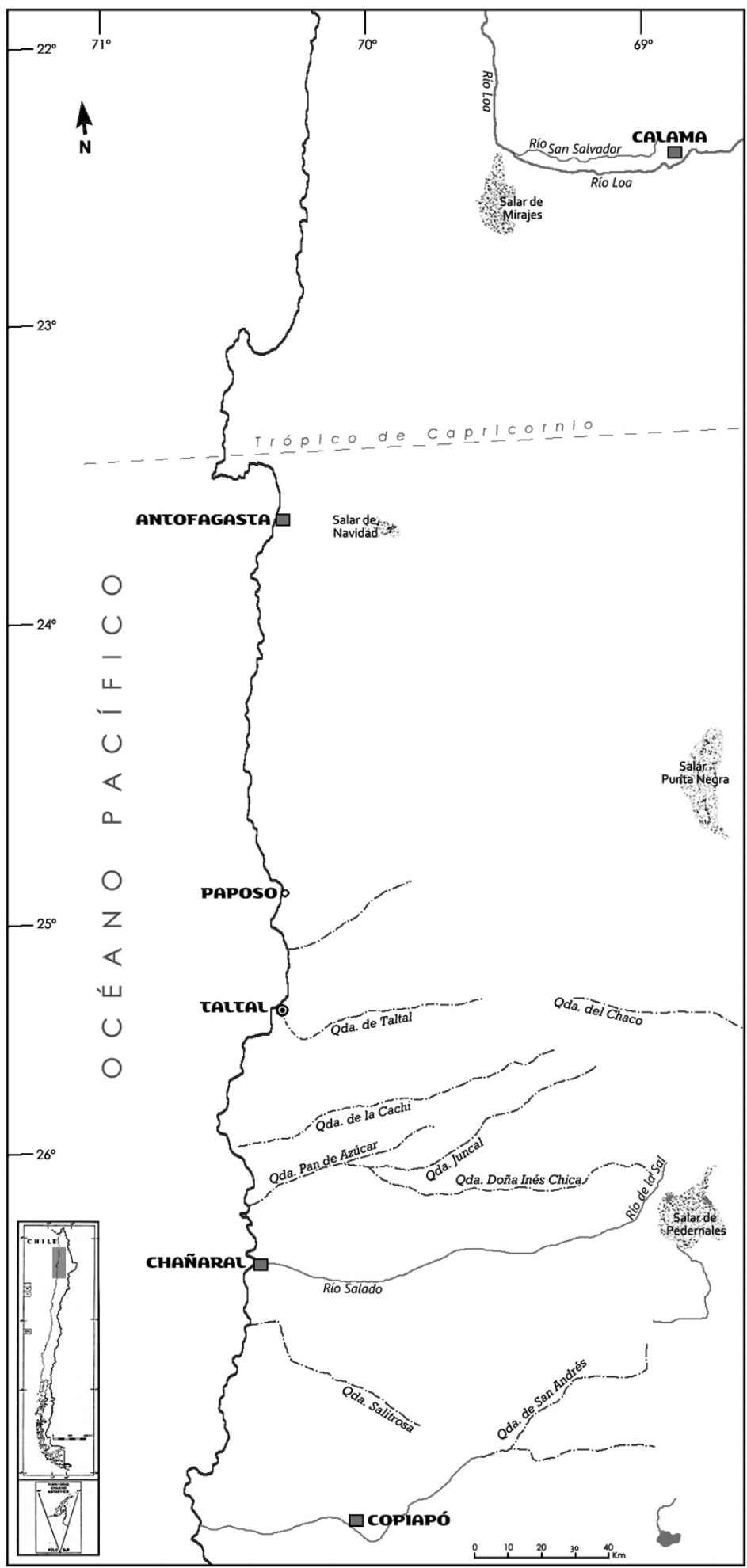

Figura 1. Mapa del área de estudio.

Map of the study area. 
fuentes, que den cuenta de la constante práctica de extracción minera, desde la prehistoria hasta nuestros días. El éxito ha sido rotundo en terreno para la época prehispánica y actual. No obstante, la búsqueda de documentos coloniales inéditos no ha sido exitosa en una primera aproximación, lo que dificulta advertir continuidades y transformaciones durante algunos segmentos históricos, en particular entre los siglos XVI y XVIII. Mayor información se encuentra para el área de estudio en archivos manuscritos y especialmente en impresos de síntesis a partir del siglo XIX, aunque con escasas referencias, si las hay, a la población local ya mestizada, como actor minero.

El hecho de que en el período colonial el extremo norte de la Capitanía General de Chile, territorio de nuestra investigación, no presentara núcleos poblacionales relevantes y no tuviese absolutamente definidos sus límites, es un problema sobre el cual existen detallados estudios (Amunátegui 1987 [1863]; Eyzaguirre 1994 [1967]; Eyzaguirre y Silva 1966; Hanisch 1984). Esta situación implicó que esta franja limítrofe costera recibiera escasa atención documental, en su calidad de espacio burocráticamente poco considerado, lo que cambia al iniciarse la época republicana y más aún, luego de la Guerra del Pacífico, cuando Chile anexa los territorios de Arica, Tarapacá y Antofagasta. Por el contrario, la documentación colonial escrita es muy abundante desde Copiapó hacia el sur y de Tarapacá hacia el norte por la costa, donde se establecieron asentamientos administrativos coloniales. En las tierras altas de Antofagasta hay algunas noticias de actividad minera colonial-española-indígena, como ha sido documentado por Melero y Salazar (2003), Salazar et al. (2005) y Núñez (2006).

\section{La Provincia de Antofagasta. Un gran Foco de Atracción Minera}

Los indios cateadores recorrían los cerros mirando su color, que era indicio mas seguro para buscar los arranques y minerales, buscando talvez los yacimientos de cuarzo, que es donde suele encontrarse el oro en ocasiones, el color verde silicatado llamado "llanca" por los indígenas, identificaba el cobre (Flores s/f:2).

La cordillera de la costa de la región de Antofagasta contiene algunos de los depósitos minerales más ricos del país. En el sector de Taltal se constatan explotaciones de oro, plata, hierro y níquel desde época prehispánica y hasta la actualidad (cfr. Salazar et al. 2010).

No obstante encontrarse invisibilizada en la documentación histórica, el aporte de la población indígena y mestiza-local ha sido crucial en esta larga historia minera, ya que han sido ellos quienes descubrieron y dieron a conocer las localizaciones de algunos de los grandes yacimientos y han proporcionado la mano de obra necesaria para su explotación, así como diversos bienes de consumo fundamentales para el funcionamiento de las faenas extractivas incluso hasta la actualidad.

Millán (2004:16-18), por ejemplo, hace notar la cantidad de británicos que arribaron al país, luego que las minas de Cornwall se agotaron después que Inglaterra durante el siglo XVIII fuera el mayor productor de cobre a nivel mundial. Ellos aportaron capitales y organizaron, junto con los empresarios chilenos, la producción de cobre en grandes cantidades, enriquecida con su larga experiencia de industrialización (Palmer 2004:1). Fue con la Independencia que hubo mejores oportunidades para el avecindamiento de estos extranjeros, ya que bajo la corona española las actividades mineras estaban prohibidas a los extranjeros y sólo se autorizaba la radicación de irlandeses, por ser de religión católica.

Otros actores de gran relevancia en la historia minera de Taltal y la costa, en particular durante la época republicana temprana, fueron los mineros cateadores, llamados Exploradores del Desierto, siendo famosos en el norte grande por su empeño, tesón y por las fortunas amasadas gracias a los minerales. Entre ellos destacan los señores Diego de Almeida, José Antonio Moreno y José Santos Ossa (Bermúdez 1960; Espinoza 1980 [1979]:31-49; Gimeno 2008:56; Millán 2004:34-39), que levantaron grandes proyectos, gracias al trabajo de anónimos hombres que se convirtieron en barreteros, apires, cancheros, aguateros y arrieros que transportaban el mineral.

En cuanto a la tecnología minera y metalúrgica, los británicos modernizaron progresivamente las faenas, modernidad que coexistía con los modos antiguos en donde en un socavón inclinado el barretero avanzaba en un frente cerrado siguiendo la veta. Hecha la tronadura para extraer el metal, los apires llenaban sus capachos ${ }^{2}$ con aproximadamente 50 kilos, saliendo a la superficie por sus propios 
pies. En las fundiciones se usó combustible de leña, consumiendo en exceso árboles nativos del norte como el chañar y el algarrobo, pero ya a mediados del siglo XIX se empezó a usar carbón en las fundiciones (Millán 2004:40-41).

La dura y violenta realidad que se vivía en torno a la minería de mediados del siglo XIX se puede graficar a través de las ilustrativas y abundantes descripciones que aparecen en el libro Andanzas de un Alemán en Chile de Paul Treutler (1958), donde, sin anhelos de crítica social, el autor caracteriza los medios socioculturales de los centros mineros, las condiciones laborales, sanitarias, la comercialización y las disputas entre los distintos actores.

Más tarde, la pequeña minería indígena y mestiza vivió un auge sostenido hasta la década de 1970, época en la que el retiro del apoyo estatal y el fomento de la inversión transnacional llevaron al colapso la modalidad de minería artesanal o del pirquén (Yáñez y Molina 2008:21-22).

\section{Área de Estudio: Taltal y Paposo}

Nuestra área de estudio (Figuras 1 y 2) posee gran riqueza mineral. Geológicamente se ha definido la franja Taltal-Paposo correspondiente a la franja metalogénica de la cordillera de la Costa, con una gran variedad de depósitos metalíferos en su mayoría encajados en rocas volcánicas e intrusivas del Jurásico medio-superior, y en menor medida del Cretácico inferior, entre los que destacan los estratoligados de cobre, con plata subordinada, los vetiformes de cobre y oro, y por último vetas menores de cobre, oro, hierro, manganeso, mercurio y níquel (Boric et al. 1990). Muchos de estos yacimientos han sido explotados a lo largo de la historia humana de Taltal y Paposo. En efecto, a diferencia de lo que asumimos comúnmente, la vinculación de Taltal con la minería no es un fenómeno reciente, sino que se remonta a momentos prehispánicos tempranos, incluso hasta las ocupaciones humanas más antiguas de la zona, correspondientes al denominado Complejo Cultural Huentelauquén (Castelleti et al. 2010; Llagostera 2005). Éstos fueron los primeros mineros de la localidad y la región.

\section{Minería prehispánica}

Estudios recientes han demostrado que desde hace cerca de 12.000 años los cazadores-recolectorespescadores Huentelauquén explotaron una mina de óxidos de hierro conocida actualmente como San Ramón 15 (Figura 3), siendo la mina más antigua conocida hasta la fecha en América (Salazar et al. 2011. Los óxidos de hierro jugaron desde entonces un rol destacado dentro de la ritualidad y la vida cotidiana de las poblaciones locales. A lo largo de todos los períodos de la prehistoria los pigmentos rojos y amarillos fueron empleados en los rituales funerarios para pintar el cuerpo de los difuntos, las ofrendas que los acompañaban a la otra vida o la propia tumba. También se ha documentado el uso de estos pigmentos con fines prácticos, tales como para tratar los cueros (Vivar 1979 [1558]). Hasta entrado el siglo XX las poblaciones locales continuaban explotando óxidos de hierro de la cordillera de la Costa con el objeto de preparar las pieles para fabricar balsas de cuero de lobo, tal como pudo observar Augusto Capdeville en la década de 1920 (Capdeville 2010). Posiblemente el uso de estos pigmentos incluyó la pintura corporal, tanto como protector solar como con fines estéticos. El cronista español Lizárraga 1987 [1594-1608]) describe la piel de los changos de la costa arreica como roja producto del consumo de sangre de lobo marino, pero es muy posible que en realidad haya sido el uso de estos pigmentos la causa de tal coloración. Lo cierto es que el uso de los óxidos de hierro ha estado presente a lo largo de la prehistoria e historia reciente de los cazadores-recolectores-costeros de Taltal. Y para procurarlos la actividad minera fue esencial.

Pero éste no fue el único mineral explotado por los indígenas precolombinos en la zona. A lo menos existen evidencias de la explotación local de minas de cobre, tal como reconoce tempranamente Philippi en el siglo XIX (Philippi 1860:29; véase también Solari 1966:11). El cobre parece haber sido trabajado en forma sistemática sólo a partir del período Intermedio Tardío (ca. 900-1.400 d.C.), es decir, varios milenios después de que se iniciara la minería de óxidos de hierro en la zona. A diferencia de ésta, la minería del cobre tenía por propósito la fabricación de objetos metálicos, fundamentalmente instrumental para la captura y procesamiento de recursos marinos tales como anzuelos, chopes, poteras y barbas de arpón (Salazar et al. 2010). Para elaborarlos fue necesario no sólo dominar la actividad minera, sino también una tecnología mucho más compleja, cual fue la metalurgia. Todavía en el siglo XIX, los grupos locales de Taltal y Paposo elaboraban sus propios anzuelos de cobre, metal 


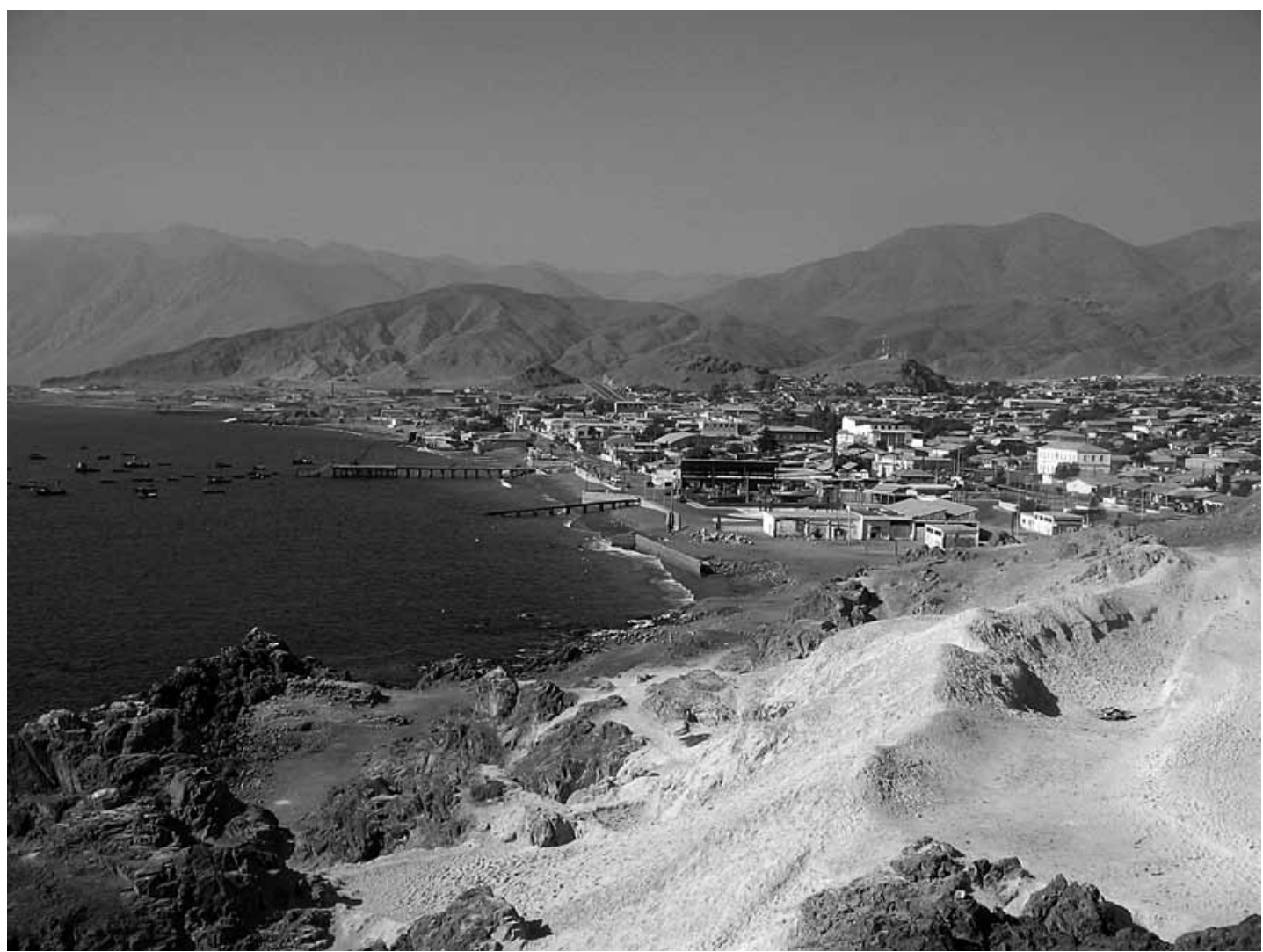

Figura 2. Bahía de Taltal.

Bay of Taltal.

preferido sobre el hierro por su resistencia y durabilidad (Matte 1981:58).

No sabemos si los habitantes de la costa de Taltal explotaron también otros minerales durante la prehistoria. Si bien los indígenas precolombinos del norte de Chile trabajaron además el manganeso, el oro, la plata y el níquel, a la fecha no existen evidencias certeras de que haya habido explotaciones de estos minerales en la costa taltalina. No obstante, la minería de los óxidos de hierro y posteriormente del cobre fue una actividad importante dentro de los sistemas de asentamiento y la organización económica de las poblaciones locales por milenios. En efecto, puede afirmarse que ya desde los inicios de la colonización humana de estos territorios los grupos costeros articularon una economía mixta de caza, recolección, pesca y explotación minera. La misma articulación, aunque naturalmente a una escala distinta y en un contexto tecnológico, social y político muy diferente, se mantendrá en Taltal hasta nuestros días.

\section{Narrativas}

\section{Contextos Taltal-Paposo}

Una historia interdigitada es indudablemente común a estas localidades, a pesar de que Taltal comienza su existencia bastante más tarde que Paposo, que ha sido núcleo poblacional durante siglos.

Especialmente para Taltal, han sido los procesos de desarrollo de la explotación minera los que lo han creado y sostenido, a partir de la segunda mitad del siglo XIX (Arce 1997 [1930]; Bermúdez 1963; Darapsky 2003 [1900]). Este devenir minero ha repercutido también en la realidad de Paposo una vez que fue incorporado a los circuitos de explotación, aunque ha mantenido sus dimensiones de poblado pequeño. Por su parte, la ciudad de Taltal creció, poblándose con gente venida del sur, fundamentalmente pirquineros del norte chico y trabajadores del centro sur, usualmente 


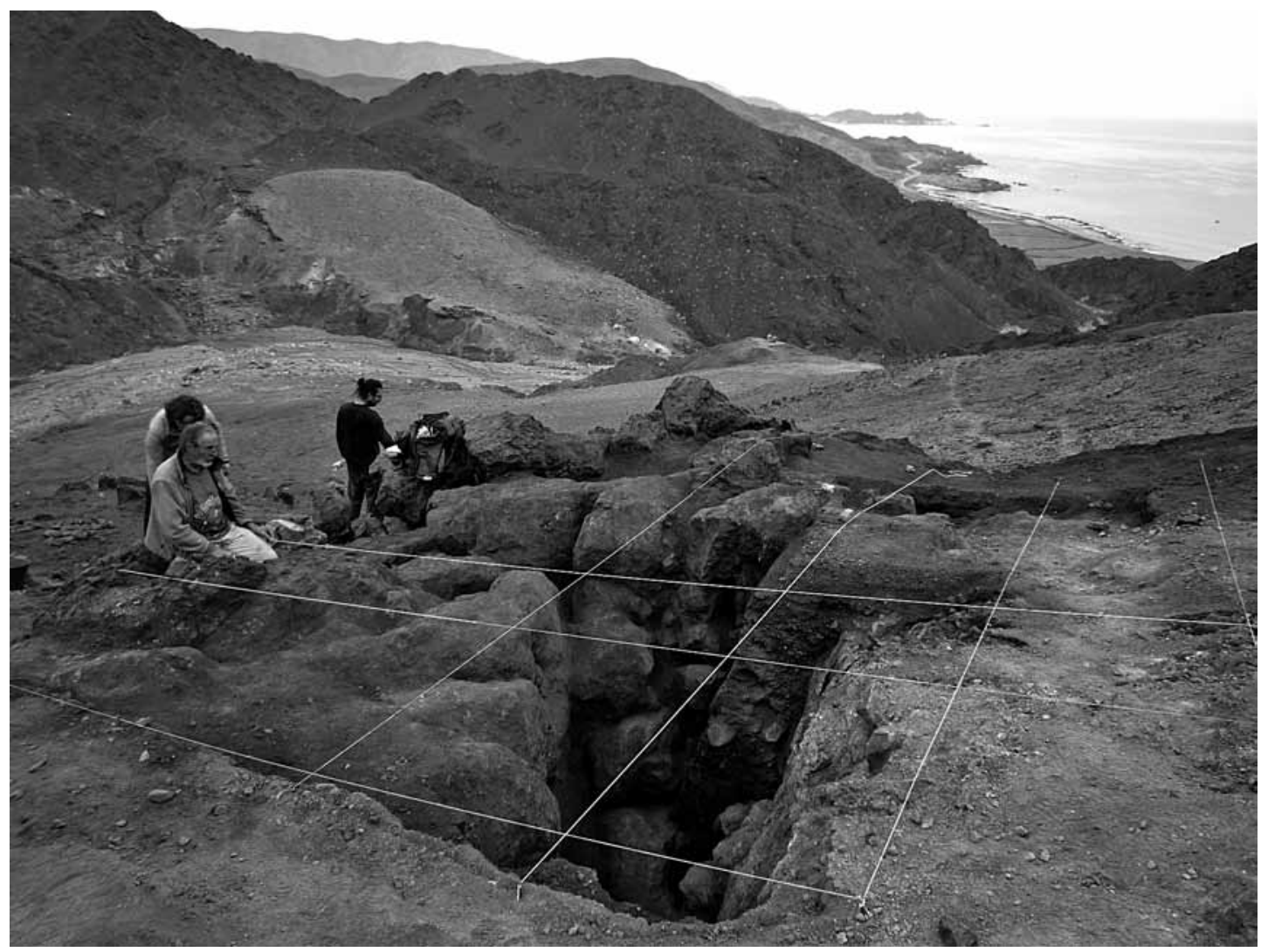

Figura 3. Mina San Ramón.

San Ramón mine.

campesinos que se convirtieron a la minería, así como inversionistas extranjeros.

Como a una Nueva California, acuden a Taltal, allá por los años 1845 oleadas de hombres de diferentes lugares del país y de otras lejanas y exóticas naciones, como Italia, de la antigua Dalmacia hoy Croacia, de Inglaterra, España, China, Palestina, Grecia (Gimeno 2005:12).

El lucro del cobre, de la plata y después la ofensiva industrial salitrera cambiaron radicalmente las condiciones de vida de las poblaciones y su relación con el entorno.

A diferencia de lo que se creyó durante mucho tiempo, ésta no era esa región prácticamente despoblada que nos heredó el imaginario colonial (Martínez 1998) y que establecía una visión de los habitantes como seres aislados y "salvajes", lugares donde el desarrollo de la humanidad estaba condicionado a las más atrasadas formas de vida, concepción que se expandió desde la puna de Atacama (Haber 2000) hasta la costa. Prejuicios que para el litoral fueron aún más exagerados, debido al modo de vida costero, como queda expresado en los adjetivos utilizados en viejos documentos, "gente bruta", "bárbaros", "miserables" (Bittmann 1979). Tal fue la influencia de estas categorías, que incluso el geólogo alemán Luis Darapsky a finales del siglo XIX y principios del XX consideró que,

El desierto carece de historia. Ni siquiera posee tradiciones $[\ldots]$ los conquistadores españoles establecieron la franja inhabitada junto al Pacífico como incierta frontera entre sus reinos, pues ¡quién habría de disputarse los terrenos de este lugar! (Darapsky 2003 [1900]:249).

Aseveraciones de un conocimiento que se limita sobre el supuesto de que el valor histórico y antropológico se relaciona siempre a los esquemas occidentales de sociedad y cultura (cfr. Said 2002). 
Predisposición que deformó el reconocimiento de los otros y sus modos de vida, y que, entre otras razones, hizo que Atacama permaneciera vacía en el imaginario colectivo por años, expuesta a un sinnúmero de comentarios parciales.

La escasez de documentación también limita nuestras posibilidades de comprensión de las poblaciones indígenas y mestizas que habitan las costas de Atacama entre los siglos XVI y XVIII. De ahí que haya que recurrir a diversas fuentes, arqueológicas, etnohistóricas y aun a la memoria oral, para aproximarse a ese momento de la historia local. A partir de estas fuentes complementarias, podemos apreciar que, contrario a las concepciones oficiales coloniales y aun republicanas, sabemos que a este lugar pertenecieron muchas generaciones de familias pescadoras-cazadoras-recolectoras manteniendo un modo de vida muy semejante desde la prehistoria hasta el siglo XIX. Estos grupos desarrollaron un modo de vida ajustado al ecosistema marino, creando tecnologías de extraordinaria precisión y sencillez, fundando prácticas coherentes a las oscilaciones y tiempos costeros, donde la movilidad era un factor central sobre el que se articulaban las sociedades. Más aún, participaron de los circuitos caravaneros y de arriería que unían la costa con las tierras altas, vínculos que lograron altos niveles de especialización (Núñez 1984), que contradicen la concepción precaria que se les adjudicaba.

Como sucede en toda la costa desértica de interfluvio, estos grupos dependieron de su cercanía a las escasas fuentes de agua. Es por eso que en esta zona las poblaciones se concentraron por la línea de costa desde Taltal hasta Botija donde existían varias aguadas, lo que convirtió a ese lugar en un centro privilegiado de habitación. Al contrario, hacia el sur de Taltal existe una disminución de las vertientes costeras (Núñez y Varela 1967), lo que nos permite suponer, junto a la información etnohistórica, que el lugar donde se levantó Taltal no concentró gente como sucedía en Paposo y sus alrededores, siendo al parecer más bien parte de un circuito de explotación que lugar de asentamiento. En este sentido, el registro arqueológico se concentra en el extremo sur de la bahía, sector conocido como La Puntilla, donde se forma una caleta de abrigo, tipo de ensenada que presenta condiciones ideales para la protección de vientos, corrientes y mareas, lo que también influye en la reproducción de las especies marinas, $y$, por lo tanto, en su abundancia y en el acceso a ellas (Escobar 2009); asimismo en la quebrada aledaña, de Los Changos, Capdeville reporta población hasta bien entrado el siglo XIX, hasta que una epidemia de cólera desatada entre 1866-1867 dejó unos pocos sobrevivientes que emigraron a Paposo (Contreras y Núñez 2009:90). No obstante, quisiéramos insistir que esto no implica la vacuidad del lugar, sino que una manera de habitar específica de los grupos del litoral (Bittmann 1986; Ballester et al. 2010; Salazar et al. 2009).

Esta condición es sustentada también por los documentos existentes, donde Paposo representa históricamente el núcleo poblacional importante de la zona y objeto de un interés en relación a concesiones de tierra y encomiendas (Amunátegui 1987 [1863]; Eyzaguirre y Silva 1966; Hanisch 1984; Thayer 1925), junto a un afán evangelizador (González 1992; Matte 1981; Lazo y Téllez 1984; Oviedo 1982).

Del conjunto de informaciones señaladas en las referencias precedentes, así como de documentos revisados por nosotros en el Archivo Nacional de Chile, podemos destacar que el primer título de propiedad, de lo que luego se conoció como la hacienda de Paposo, fue entregado al Maestre de Campo don Francisco de Cisternas quien fuera Corregidor de Copiapó y vecino feudatario de $\mathrm{La}$ Serena, que recibió la merced de tierras de parte del Gobernador de Chile don Juan Henríquez de Villalobos, el 4 de julio de 1679. Esta merced de tierra tenía entre sus límites la quebrada de Paposo y su caleta, lugar de pesca de changos, hasta la punta de Miguel Díaz, y de oeste a este desde el océano a la cordillera de los Andes. Luego en 1791, el gobernador O'Higgins dispuso medidas a favor de los indígenas de Paposo, especialmente para el desarrollo de la pesca, sin que el dueño les pudiera exigir retribución alguna. De esta década, existen un par de informes del diputado territorial, uno de los cuales indica que hay 152 habitantes, la mayoría familias pescadoras dispersas por la costa (Hanisch 1984:206-207). Por su parte, las informaciones entregadas a partir de las misiones religiosas hacen presente la preocupación de la iglesia católica por los habitantes de Paposo. Se conocen tres misiones, la más antigua y probablemente más relevante para el lugar, debido a la iniciativa que tuvo el misionero Rafael Andreu y Guerrero, duró cinco años que se estiman entre 1796 y 1800 (González 1992; Oviedo 1982). Le sigue la realizada por dos franciscanos, Barrera y Araya, a comienzos del siglo XIX, posiblemente entre 1803 
y 1807, quienes realizaron una matrícula de los habitantes (Lazo y Téllez 1984); y finalmente, la de tres sacerdotes dirigida por Rafael Valdivieso en 1841, que deseaban misionar en el lugar, por la falta de "pasto espiritual que hay en el Departamento de Copiapó y las tolderías de Paposo" (Matte 1981:51). Las descripciones de las tres misiones indican que si bien Paposo es un centro poblacional la mayoría de las familias se trasladan a lo largo de la costa en busca de recursos marinos. Se menciona además la existencia de habitantes dedicados a la minería y a la crianza de animales. Destacan la pesca del congrio, la elaboración de charqui y su comercialización, que parece estar bien organizada. La población estaría compuesta no sólo de indígenas, sino que también de mestizos.

Cercano a esa fecha, Bermúdez (1962) entrega un dato en el que se habla sobre unos changos de Cobija, otro centro indígena importante, que están pescando en Paposo en el año 1793 y donde además se advertiría que no tienen residencia fija en ninguna caleta. Estos viajes desde Cobija a Paposo parecen haberse realizado en forma frecuente (ver p.ej., Sayago 1973 [1874]:505).

En 1813, en plena guerra de emancipación y al levantarse por orden de la Junta de Gobierno, el censo del país, se efectuó éste en la caleta del Paposo, uno de los pocos caseríos de la región del desierto, donde entonces habitaban sólo 570 individuos de origen indio, mestizo y mulato (Eyzaguirre 1994 [1967]:51; Censo de 1813 (1953)).

Luego en 1907, otro censo señala la existencia de 267 hombres y 174 mujeres con un total de 441 habitantes, de los cuales 15 eran extranjeros (Matte 1981:55). El francés Julian Mellet viaja por Suramérica durante doce años, y publica el libro Viajes por el Interior de la América Meridional (1900 [1824]). Allí cuenta de su viaje de Copiapó a Paposo a principios del siglo XIX, comentando, entre otras cosas, que ésta era una aldea habitada por indios tributarios, gobernada por un subdelegado y un cacique, que hacía de intérprete entre los indios y el subdelegado, quien era la autoridad máxima. Estima la población en 400 personas aproximadamente. En la década de 1850 Philippi hace campamento en Hueso Parado, localidad unos kilómetros al norte de Taltal, y describe que cerca de su toldo "había muchos ranchos de changos"3 (Philippi 1860:17), hechos con cuatro costillas de ballena o troncos de quisco, tapados con cueros de lobos marinos, cueros de cabras, algas secas y harapos. El estómago de lobo lo usaban para almacenar agua. Denota que se visten como todo el mundo, se alimentan de pescado y mariscos y, aunque son muy educados, han perdido su propia lengua, empleando sólo el castellano (Philippi 1860:18-19). Luego llega hasta Paposo donde divisa una veintena de casas de changos; allí encuentra a unos atacameños que se mostraron muy desilusionados de no poder comprar pescado, "porque la mayor parte de los changos había preferido trabajar en las minas" (Philippi 1860:22-23). Relata que la Hacienda Paposo es de una familia de apellido Gallo y que se extiende entre las localidades de Hueso Parado y Miguel Díaz; señala que allí viven changos independientes. Esta hacienda tenía entre 30 y 40 mulas que se alquilaban para transporte de metales, agua y leña para las minas. En Paposo había un almacén en la época, que según Philippi era de "precios fabulosos". El pago que recibían no era en plata, sino en pescado seco. Algunos años después, en 1860, el viajero, químico e industrial inglés Bollaert visita Paposo y lo describe como centro de intercambio indígena, donde truecan congrio seco por coca, harina, ropa o maíz, remarcando también que los propios indígenas hacen expediciones al interior para trocar pescado por otros productos (Bollaert 1860).

\section{La Minería en la Narrativa Histórica y Etnográfica}

Puede decirse que esta región debe su vida y esplendor a la minería, fuente fecunda e inagotable de su progreso y base angular de su actual desenvolvimiento. Por eso convergieron aquí capitales e iniciativas que buscaban actividades más prácticas y eficientes donde impulsar su espíritu de empresa, ya que este jirón del antiguo Litoral, como ninguna otra sección del territorio, hasta hoy, es el depositario portentoso de cuanta riqueza pueda encerrar la minería del mundo (Arce 1997 [1930]:417).

Tuvieron que aunarse esfuerzos de cateadoresexpedicionarios, pirquineros y de todos quienes persiguieron la riqueza mineral, para que la ambición de otros hombres con otras formas de habitar comenzaran la construcción de nuevos poblados. Si bien la 
costa arreica de la actual región de Antofagasta fue bien conocida por sus recursos cupríferos durante el período boliviano (1825-1881), la explotación cuprífera durante este período se centró en torno a las localidades de Tocopilla y, fundamentalmente, Cobija. Las minas de Cobija llegaron a tener bastante importancia a nivel regional e incluso en los censos de la época se advierte una creciente migración de mineros desde el interior de la provincia hacia la costa (Cajías de La Vega 1975). No obstante, en las costas de Taltal y Paposo este nuevo proceso social y económico se consolida recién en la segunda mitad del siglo XIX. El 24 de diciembre de 1853, el naturalista alemán Rudolph Philippi, que exploraba la región de Atacama encomendado por el Gobierno de Chile, divisó el desmonte de una mina, luego una bandera chilena y después "escondidos entre los peñascos, el establecimiento del Cobre" (Philippi 1860:29). De allí salió a recibirlo amablemente el dueño, José Antonio Moreno, quien había instalado el asentamiento hace algunos meses.

El naturalista describe paisajes, flora, fauna, aguadas, mientras alcanza Caleta el Cobre, donde precisa que Moreno trabajaba con alrededor de 60 mineros, lamentándose de no poder dar empleo al doble, por la escasez de agua (Philippi 1860:29).

Más conocido como el manco Moreno, debido a la pérdida de su brazo derecho, José Antonio Moreno (Figura 4) era uno de los más influyentes impulsores de la industria minera en la región y junto a Diego de Almeyda, los más recordados exploradores del desierto de Atacama. Oriundo de Copiapó, se cuenta que tenía gran fuerza de voluntad y que, a diferencia de Almeyda -más conocido como el Loco-, fue más metódico en su actuar concentrándose en la región de Taltal (Bermúdez 1960). Es en esas exploraciones que en 1851 encontró un rico filón de cobre nativo donde un par de años más tarde comenzó a levantar un establecimiento para explotarlo. Según Philippi (1860), aquella ensenada tenía el nombre de El Cobre desde tiempos inmemoriales y supuso que los changos habían sacado cobre de allí desde antes de la llegada de los españoles, pues divisó unas minas antiguas.

Esta mina fue muy importante durante la década del cincuenta, pero Moreno siguió sus expediciones hacia el sur encontrando otros yacimientos, entre los que destaca una ancha veta llamada Reventón en el lecho de la quebrada que desemboca en Paposo (Darapsky 2003 [1900]). Asimismo, continuó encontrando y explotando minas de cobre en los alrededores, que son muy ricos en ese mineral. "La riqueza de las minas descubiertas, especialmente la del cerro Reventón cerca de Paposo, dejó gran fortuna a José Antonio Moreno" (Bermúdez 1963:286).

Sobre el particular, Francisco San Román destaca el espíritu emprendedor de Moreno, y su incidencia en la fundación de pueblos en Taltal, Paposo y en El Cobre, junto a la construcción de caminos para emprender la conquista industrial del desierto (San Román 1896:174-175). El autor considera que las minas de Paposo "han constituido una de las aglomeraciones más enormes de riqueza cobrera que haya existido en Chile" (San Román 1894:368). Así lo subraya también Darapsky (2003 [1900]), quien se refiere al tremendo esfuerzo desplegado por Moreno, su hijo y los leales trabajadores que le servían.

Obviamente, la producción de estos enclaves mineros necesitaba ser cargada y transportada, lo que durante varios años se hizo a través de carretas, que llevaban el mineral hasta las embarcaciones. No conocemos el dato preciso del lugar que utilizaba Moreno en esos primeros años, pero, según algunas versiones y por deducción, es bastante probable que haya sido desde los muelles de Paposo o caleta El Cobre. Sin embargo, hay certeza que cerca del final de la década del cincuenta Taltal ya funcionaba como puerto de embarque, aunque no poseía una autorización oficial. Esto generaba mucha demora, pues debían obtener un permiso del Intendente de Atacama y llevar a bordo a un guardia desde Caldera, donde se encontraba la aduana. Debido a esto, Moreno solicita al gobierno que declare puerto a Taltal, lo que queda estipulado en un Decreto del 12 de julio de 1858 -fecha que se estableció como el aniversario de la ciudad-. Tal como informa Darapsky (2003 [1900]:211), "Taltal debe su primer poblamiento exclusivamente a la extracción de cobre".

Una cita encontrada en el Archivo Nacional, describe la riqueza mineral de la zona:

Desde Caldera a Mejillones que es considerado el término de la república acia (sic) el norte existen caletas y puertos de mucho importancia a causa de la riqueza de esos lugares, entre los cuales nombraremos a Obispito, Flamenco, Chañaral de las Ánimas, Taltal, Paposo y Cobre. En los tres últimos puntos el (i?) Moreno ha formado hermosos establecimientos y en 


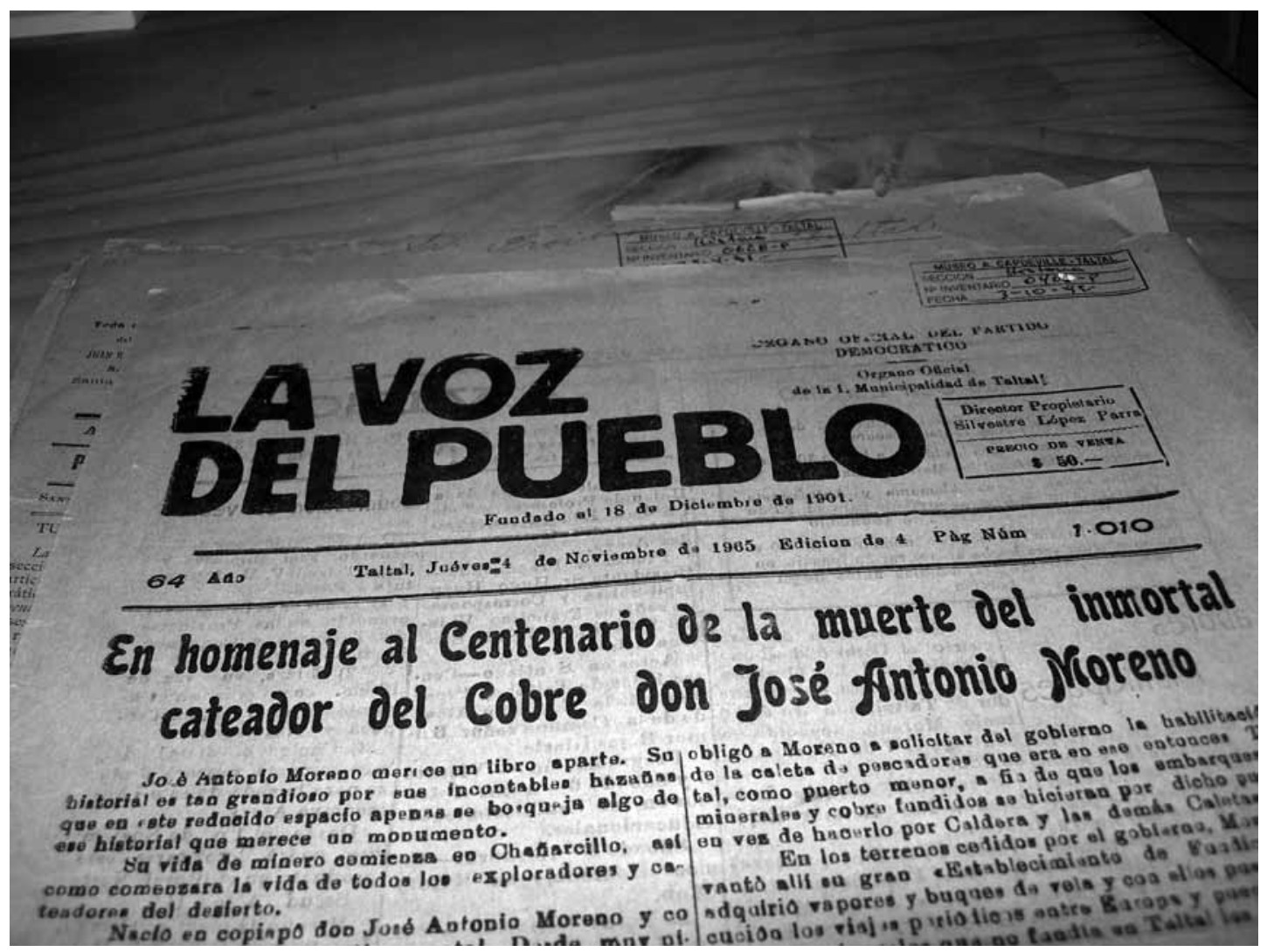

Figura 4. Periódico La Voz del Pueblo, Taltal. 1965. Archivo Museo Augusto Capdeville Rojas, Taltal.

Newspaper La Voz del Pueblo, Taltal. 1965. Museo Augusto Capdeville Rojas Archive, Taltal.

uno de ellos hornos de fundición (Archivo

Claudio Gay, 1854-1860: vol. 42, foja 159).

De origen más tardío que la explotación del cobre, pero de gran importancia para el desarrollo de Taltal fueron los yacimientos de plata especialmente Cachinal de la Sierra y Esmeralda; del mismo modo, los descubrimientos de oro en el cerro Guanaco y la sierra Overa (Darapsky 2003 [1900]:218). Fue literalmente la época de oro de Taltal. Según este mismo autor, el departamento de Taltal en 1890 tenía 3.300 yacimientos de minerales. Documentos inéditos de la época resaltan constantemente este esplendor. En referencia al mineral de Paposo, se señalaba a inicios del siglo XX que:

Este es el más antiguo i seguramente el mas importante de este departamento, es mui estenso i lo componen como 300 minas, casi todas de gran importancia: es famoso por la anchura i constancia de sus beneficios, encontrándose algunas minas con vetas de mas de 40 metros de ancho con minerales de $10 \%$ el común de cobre i minas como la 'Reventón' con mas de 300 metros de profundidad i que ha dado mui ricos minerales desde la boca mina hasta su mayor hondura. Pertenece a la Sra. Julia Moreno de Latorre i hoy está vendida ad-referendum a don Eduardo Framm por la suma de $\$ 2.500,000,00$. (sic)"(Intendencia de Antofagasta, vol.24: Memoria de la gobernación de Taltal del año 1923).

Sin embargo, esto va a cambiar durante la década de los setenta, específicamente a partir de 1871, cuando comienzan las exploraciones de búsqueda de yacimientos salitreros en el territorio chileno del desierto de Atacama. Ese año, la exploración financiada por los santiaguinos Concha y Toro y Rivas descubrió grandes salitrales 
al interior de Taltal en el sector de la aguada de Cachiyuyal, conocida también como Agua Verde. No obstante, la existencia de salitre en la región era conocida por Almeyda y Moreno desde hacía varios años, pero como sus intereses eran otros lo habían dejado pasar. Incluso le habían informado a Philippi cuando estuvo con ellos en El Cobre, aunque éste no lo consideró del todo. En 1872 Emeterio Moreno salió desde Antofagasta con una expedición hacia el sureste. Próximo a la aguada de Aguas Blancas encontró un salar con auspiciosos depósitos salitrales que incluso contó con un informe aprobatorio, pero que no pudo explotar por falta de recursos e inversionistas que confiaran en la viabilidad del proyecto. Así quedaban descubiertas las dos principales zonas salitreras en territorio chileno (Bermúdez 1963).

Estos y otros hallazgos habían sido impulsados por dos razones fundamentalmente. La primera, es que la gran extensión de labores alcanzada por la empresa salitrera de Antofagasta (Melbourne Clark y Cía.) estimulaba la ambición de los mineroscomerciantes, a lo que se agregó la nulidad por ley de parte del gobierno boliviano de las adjudicaciones y concesiones que había entregado Melgarejo antes de ser derrocado en enero de 1871. Mientras tanto, en el ámbito político, José Victorino Lastarria se preocupó fuertemente por la explotación minera. Durante el ejercicio de su cargo de senador presentó un proyecto de ley que apoyaba a la minería de la región, que no estaba rindiendo de la mejor forma.

Posteriormente, al ser incorporado como Ministro del Interior en el gobierno de Pinto en 1876, aprovechó de insistir en su preocupación e impulsó medidas al respecto. Quizás la preocupación mayor eran las dificultades para transportar el mineral debido a las características del territorio. Lastarria por tanto consideró fundamental el establecimiento de puertos y la construcción de caminos y ferrocarriles, para lo cual ordenó la conformación de la Comisión Explotadora del Litoral Norte de Atacama, que se encargaría de estudiar las posibilidades. Ésta se embarcó en el barco de guerra Abtao, comandado por Rondizzoni, donde también iban los ingenieros Plazolles y Sierralta. Los resultados consideraron que la caleta de Remiendos reunía las condiciones buscadas para convertirse en puerto menor, lo que fue declarado en abril de 1877, junto al cambio de nombre de la caleta por el de Blanco Encalada. Poco tiempo después se decidía el establecimiento de poblaciones en este lugar y en Taltal, con 23 y 11 manzanas respectivamente. Sin embargo, cuando se disponían a trazar el camino por la quebrada de Remiendos, se dieron cuenta que era más favorable sacar el mineral, especialmente el de Aguas Blancas, por Antofagasta.

También se le había encargado al reconocido geólogo Pedro Pissis que hiciera estudios en la zona. Según éstos, concluyó que Taltal debía ser el puerto principal por el que se exportara no sólo el salitre, sino que todos los productos del interior. A raíz de esta apreciación, Taltal, que aún se presentaba como centro de bodegas, embarques, provisiones y en donde sólo existían algunas casas de material ligero, comienza a crecer, lo que sigue aumentando una vez que se construye el ferrocarril que une la bahía con el interior (Bermúdez 1963). Dentro de este destino minero, a fines del siglo XIX, Taltal exportaba borato de cal, cobre en barra, ejes de cobre y plata, oro y salitre y yodo en cantidades, no obstante las dificultades para una comunicación fluida y económica (Espech 1897). Por su parte, Herrmann (1900) hace notar que siendo las minas de la región de Antofagasta de tan buena ley, muchos prefieren trabajar las minas con su tecnología artesanal y vender directamente a los compradores. En cuanto a Taltal y otras localidades de la región son mencionadas porque los ferrocarriles que llevan el mineral a los puertos tienen tarifas muchísimo más altas que los trenes más sureños.

En 1881, Stevenson y Linnich, ejecutivos de The Taltal Railway Company limited, comparecen en Valparaíso con un capital de 500.000 libras esterlinas para poner en marcha la construcción del ferrocarril. Así la empresa inglesa "asumía el control completo de los trabajos de construcción de la línea férrea de Taltal a Refresco" (Echeverría 2009:142). El ferrocarril quedó operando en 1889, cumpliendo con excelencia sus tareas tanto para el transporte de carga como de pasajeros (Echeverría 2009:143).

Paradojalmente en ese tiempo, aproximadamente entre 1853 a 1890, Chile se convierte en uno de los productores de plata más importantes del mundo; así es que la minería de la plata en el siglo XIX en Taltal fue muy exitosa, aunque se explotó con una tecnología más tradicional y arcaica que el cobre. Sin embargo, en 1891 se produjo un fuerte descenso en la producción de cobre, cerrando varias minas a nivel regional y muchas en Taltal (Millán 2004:5051), lo que nos demuestra el eterno vaivén en los precios de los minerales en toda época. La industria 
salitrera acapara desde entonces los principales capitales y proyectos de extracción minera de la zona (San Francisco et al. 2009).

En 1911 Taltal es con propiedad uno de los cinco puertos de la región de Antofagasta (González 2008). Los barcos llegan a cargar sus bodegas con minerales, principalmente el salitre del cantón de Taltal (San Francisco et al. 2010) y el tren recorre el desierto sobre los ramales que comunican las oficinas y que van a dar al litoral. Las políticas del gobierno daban resultados, la eliminación tributaria y la creación de vías para el transporte atraían a industriales e inversionistas nacionales y extranjeros y por supuesto a trabajadores.

Es importante destacar que estos flujos de personas, para el caso de la mano de obra, se generaron principalmente a raíz de una institución que ha sido conocida como el Enganche, institución que funcionó también en la colonia y que tenía como fin suministrar mano de obra a las oficinas salitreras. Había casas enganchadoras "y no fueron meras agencias de empleo, pues recurrieron a las más diversas estrategias de captación de hombres aptos para el trabajo" (González 2002:145), que incluían agentes especializados, como relata Andrés Sabella en El "enganchador", de su obra Norte Grande (1959):

Las compañías sabían elegir, de entre los viejos y ladinos hombres de la pampa, a los que servían de cantos de sirena, en el Sur, para arrancar de los ranchos a los mocetones ebrios del sueño de la fortuna. Era un arte como cualquier otro: un arte difícil que exigía el labio presto y la voz plena (Sabella 1959:98).

Las compañías les daban dinero para los gastos y para que pudieran impresionar a los futuros enganchados. Entonces el enganchador partía de viaje al Sur, y buscando personas desplegaba sus artimañas, que incluían su aspecto y los relatos acerca de lo fácil que era ganar dinero en la pampa. Narrativas etnográficas denotan bien la labor del "enganche":

Él se vino en los enganches a la salitrera Alemania. Malegrán, Cuadra, eran familias salitreras, varias de las cuales se asentaron en Taltal cuando se acabaron las salitreras del cantón, incluso varios viven en una misma calle, se conformó como un barrio de familias salitreras.
Al igual que muchos de los inmigrados a esta zona, llegó de la cuarta región, del interior de Vallenar. Su papá era minero y ellos con su hermano mayor cuidaban los animales hasta que su papá se murió y ellos empezaron a trabajar la mina del papá. El tenía 9 años y su hermano 10. El lugar donde vivían con sus papás se llama Los Morteros al interior de Vallenar, donde tenían cabritas.

Después de hacer el servicio militar en Copiapó, se enganchó a la oficina Alemania. Mucho trabajo y mucho alcohol, hasta que hace como 5 años dejó de tomar. Dice que por lo mismo lo engañaban mucho. Cuenta que él era muy reconocido como cateador de minas, sabía un montón y tenía muy buen ojo, cosa que es muy valorada por los mineros; de alguna manera es capaz de "leer" las vetas, y puede ir prediciendo hacia dónde van y con cuánto valor de mineral. De hecho cuenta historias donde él sabía más que geólogos o ingenieros que llevaban algunos empresarios, pero que él llegaba miraba el trabajo que estaban haciendo y se daba cuenta de que estaban equivocados, entonces les decía cómo y por dónde y realmente le achuntaba. El problema es que como era tan bueno para tomar, muchas veces lo engañaban, nunca pudo capitalizar su saber, sino que otros se aprovecharon de él. Lo resume así " $\mathrm{Pa}$ ' ser jefe me faltó un poquito más de letra". (Narración de JOV, residente en Taltal).

Junto al desarrollo de la industria y el crecimiento de Taltal, se producen importantes complejidades socioculturales ocasionadas por los desplazamientos de personas. Imposición de nuevas reglas en la composición del trabajo, en los modos de vida y la creación de núcleos urbanos sobre la base de inmigrantes de diferentes lugares. Éstos deben aprender a convivir con las particularidades socioculturales que cada uno trae y comenzar a formar otras junto a sus nuevos coterráneos. Tal como plantea el historiador Manuel Fernández, en la región de Antofagasta se forma un proletariado específico que se diferencia del de Chile central, pues se ubica en una zona demasiado alejada de los lugares de origen, lo que no les permite a los obreros "volver al campo", obligándolos al no poder 
retomar esos vínculos, a generar su propia cultura (Fernández 1987). Asimismo, esta situación se relaciona también al surgimiento de una actividad política que los represente frente a las injusticias de los industriales, que se organiza en grupos que enarbolan ideales del anarquismo, el socialismo y el comunismo, creando una tradición que se mantiene hasta el día de hoy (Grez 2007).

Como sabemos, la industria del salitre entra en una situación de inseguridad desde comienzos de la Primera Guerra Mundial, lo que termina haciendo crisis en 1930, cuando la competencia de los fertilizantes sintéticos, de precios y la acumulación de la sobreproducción hicieron colapsar a la industria que entre 1930 y 1933 produjo la paralización casi total de las oficinas, causando graves problemas económicos, sociales y culturales. Obviamente Taltal no se eximió de esta situación, cerrando en la segunda mitad de la década de 1960 la mayoría de las oficinas. Todo el crecimiento alcanzado se fue desvaneciendo. Las personas tuvieron que dedicarse a otras actividades o simplemente emigrar de vuelta a sus lugares de origen o a los centros urbanos más grandes de la región, o comenzar a buscar nuevas oportunidades en otras partes de Chile.

No obstante, aún a mediados del siglo XX, junto a toda esta complejidad y vaivén de la actividad industrial, la cotidianeidad del quehacer vinculado a la minería se deja apreciar en relatos de migrantes que han llegado a ser taltalinos y que escriben parte de una historia inédita, rica y densa, especialmente en cuanto al quehacer de los pescadores-mineros locales:

Llega el día de la entrevista con don H. L. P. Me recibe en su casa. Tiene 75 años. Me cuenta que él es originario de Santiago y que se vino al norte con su padre al mineral de Guanaco, que está a $130 \mathrm{~km}$ al noreste de Taltal (cordillera de Domeyko), el año 1946 ó 1948. Tenía como 15 años y vino acompañando a su padre, que había conseguido trabajo. En principio eran dos años, pero el trabajo se alargó debido al aumento del precio del mineral.

Era muy sacrificado en esa época, pues había muy poca mecanización de los procesos de explotación. En esa mina trabajaban aproximadamente 300 mineros, la mayoría inmigrantes de otras regiones del país, en especial de la zona central hacia el norte, lo que reafirma los datos obtenidos en la investigación realizada en Cobija ${ }^{4}$, respecto al origen de la población, especialmente minera. En este sentido, las personas de Taltal trabajaban principalmente en las salitreras, El Cobre, La Plata y en la pesca. Me dijo que varios de los capachos eran de cuero de lobo. Los pescadores los llevaban a las pulperías de los campamentos mineros. También había capachos de cuero de vacuno, pero según él eran mejores los de lobo. Eran más resistentes. Me cuenta que también había unas botas de cuero, que en vez de tachuelas, tenían unas especies de clavos de madera. Le pregunto si espinas de quiscos y me dice que parecidas. Los pescadores, que son los que él nombra como changos, también proveían de pescado fresco y seco. Charqui de congrio que llevaban a las salitreras y a otros campamentos mineros. Agrega que los llamados changos, también vendían cuerdas de cuero de lobo para las faenas de producción minera; por tanto, podemos suponer que llevaban cierta cantidad de objetos y no sólo alimentos, para realizar trueques con los productores mineros.

Sin embargo, me cuenta también que algunos de esos pescadores o "changos", originarios de Taltal, en ciertas ocasiones se dedicaban al trabajo en las minas, a quienes reconoce como pescadores-mineros. Dice que trabajaban en la minería cuando estaba mala la pesca y algunos se quedaban y otros volvían al mar. Los describe muy "fortachos", con una gran capacidad física para los trabajos más duros.

Un dato interesante, es que los changos mineros pedían como condición que les tuvieran coca para mascar mientras trabajaban. Y agregó que esa era una tradición muy antigua que tenían los changos de Taltal, que incluso había tiendas que vendían coca en el pueblo. Le pregunto entonces, cómo reconocía quién era chango, y me responde que por el acento al hablar. ¿ $\mathrm{Y}$ cómo era ese acento? y me dice que parecido a los aymaras, aunque no muy convencido. Castellano con acento. Comenta los apellidos más comunes de changos, son Gutiérrez, Morales, Díaz (Relato de H.L.P. en Taltal, Escobar 2008). 


\section{Palabras Finales}

La riqueza minera de las localidades de Taltal y Paposo ha sido reconocida por todos sus habitantes a lo largo de más de 12 milenios de historia. La explotación y uso de estos minerales ha formado parte de los modos de vida de las poblaciones locales. En conjunto con la explotación de los recursos litorales, han conformado un sistema de vida mixto que se mantiene hasta la actualidad a pesar de las enormes transformaciones culturales, económicas, políticas y tecnológicas.

El hierro ha sido el mineral más antiguamente explotado, y todavía hoy es extraído por pirquineros. No obstante, el cobre y posteriormente el salitre fueron los minerales más importantes para entender los profundos cambios sociales y culturales de los últimos 200 años en este tramo de la costa arreica de la Región de Antofagasta. A pesar del decaimiento de la explotación del salitre en la primera mitad del siglo $\mathrm{XX}$, las actividades mineras asociadas principalmente al cobre permitieron que pirquineros y pequeños y medianos empresarios ${ }^{5}$ tuvieran trabajo y, por consecuencia, pudieran sostener la situación económica de Taltal. Es lo que ha venido sucediendo hasta el presente, donde las fluctuaciones de la demanda y precios de los minerales han ido determinando el devenir de la región y su gente, continuando con un proceso que es clave para comprender las conformaciones y transformaciones socioculturales propias de este territorio, que vinculan a habitantes y tradiciones originarias con los allegados nacionales, lo que ha generado particulares procesos antropológicos y que además ha escrito parte fundamental de la historia de Chile. Sin embargo, no podemos dejar de subrayar que si bien estos procesos, íntimamente ligados al desarrollo de la minería, son un factor ineludible para entender nuestra existencia como Nación, tienen además y han tenido graves consecuencias -abusos sociales y atrocidades como la matanza de Santa María de Iquique o los ahora reconocidos problemas medioambientales-, que de manera también ineludible nos contradicen en lo más profundo.

Es también desde esa perspectiva que debemos concebir a Taltal y Paposo ubicando su existencia en la historia de Chile, comprendida la época prehispánica y su contexto multiétnico a través del tiempo, develando los efectos de su condición de enclave de economía marítima y minera, como continúa siéndolo hasta hoy.

Agradecimientos: A los taltalinos que nos permitieron conocer sus experiencias en el trabajo de ser minero y pescador. Al Director del Museo de Taltal, antropólogo Rodolfo Contreras, por su generosidad constante con sus conocimientos y la acogida en el museo bajo su dirección. Al señor Alcalde de Taltal, por sus permanentes gentilezas. Los Proyectos FONDECYT 1080666, 1110196 y 1100951 han financiado nuestras investigaciones. Nuestros agradecimientos a los evaluadores de este manuscrito.

\section{Referencias Citadas}

\section{Fuentes publicadas}

Amunátegui, L. 1987 [1863]. La Cuestión de Límites entre Chile y Bolivia. Universidad de Santiago, Instituto de Investigaciones del Patrimonio Territorial de Chile; Colección Veritas $\mathrm{N}^{\mathrm{o}} 1$, Santiago.

Arce, I. 1997 [1930]. Narraciones Históricas de Antofagasta. Antofagasta.

Bermúdez M., O. 1960. Exploradores del Desierto de Atacama. En Viaje 323:45-48. Santiago.

- - - 1962. La vida de los Changos. En Viaje 342:7-9. Santiago.

- - - 1963. Historia del Salitre. Desde sus Orígenes hasta la Guerra del Pacífico. Ediciones de la Universidad de Chile, Santiago.

Ballester, B., A. San Francisco y F. Gallardo 2010. Modo de vida y economía doméstica de las comunidades cazadoras recolectoras costeras del desierto de Atacama en tiempos coloniales y republicanos. Taltalia Revista del Museo Augusto Capdeville Rojas 3:21-32. Taltal.

Bittmann, B. 1979. Cobija y sus alrededores en la época colonial (1600-1750). Actas del VII Congreso de Arqueología de Chile, Vol. II, pp. 327-64. Ediciones Kultrún, Santiago.

- - - 1984. Programa Cobija: Investigaciones Antropológicomultidisciplinarias en la Costa Centro Sur Andina: Notas Etnohistóricas. En Contribuciones a los Estudios de los Andes Centrales, editado por S. Masuda, pp. 101-49. Universidad de Tokio, Tokio.

1986. Los pescadores, cazadores y recolectores de la costa árida chilena: Un modelo arqueológico. Chungara 16-17:59-65.

Boccara, G. (ed.) 2002. Colonización, Resistencia y Mestizaje en las Américas. IFEA - Abya-Yala, Lima/Quito.

Bollaert, W. 1860. Antiquarian Ethnological and Other Researches in New Grenada, Equador, Perú and Chile with Observations on 
the Pre-Incarial, Incarial, and Other Monuments of Peruvian Nations. Trübner \& Co., Paternoster Row, London.

Boric, R., F. Díaz y V. Maksaer 1990. Geología y yacimientos metalíferos de la Región de Antofagasta, Norte de Chile. Boletín 40. Servicio Nacional de Geología y Minería, Santiago.

Cajías de La Vega, F. 1975. La Provincia de Atacama. 18251842. Instituto Boliviano de Cultura, Empresa Editorial Universo, La Paz.

Capdeville, A. 2010. Augusto Capdeville Rojas, notas. Taltalia 2:98-110. Museo Augusto Capdeville Rojas, Taltal.

Castelleti, J., O. Reyes, G. Maltrain, I. Martínez, P. Galarce, H. Velásquez y J.P. Ogalde 2010. Ocupaciones en abrigos rocosos en la costa de Taltal: patrón de uso del espacio desde momentos holocénico tempranos. Actas del XVII Congreso Nacional de Arqueología Chilena. Editado por L. Adán, pp. 685-695. Ediciones Kultrún, Valdivia.

Castro, V. 2009. De Ídolos a Santos. Evangelización y religión andina en los Andes del Sur. Ediciones de la Dirección de Bibliotecas, Archivos y Museos. Centro de Investigaciones Diego Barros Arana- Fondo de Publicaciones Americanistas Universidad de Chile, Santiago.

Carmagnani, M. 2006. El Salariado Minero en Chile Colonial. Su Desarrollo en una Sociedad Provincial: El Norte Chico 16901800. Centro de Investigaciones Diego Barros Arana. Ediciones de la Dirección de Bibliotecas, Archivos y Museos, Santiago.

Censo 1813. 1953. Censo de 1813: Levantado por Don Juan Egaña, de Orden de la Junta de Gobierno Formada por los Señores Pérez, Infante y Eyzaguirre. Introducción de Raúl Silva Castro. Imprenta Chile. Archivo Nacional, Santiago.

Contreras, R. y P. Núñez 2009. Nuevos antecedentes sobre la balsa de cuero de lobo en la costa de Taltal, Chile. Taltalia 2:88-97. Museo Augusto Capdeville Rojas, Taltal.

Corsín, A. 1987. Pampa e historia: minería del salitre en el Desierto de Atacama en el siglo XX. Hombre y Desierto. Una Perspectiva Cultural 13:29-38. Instituto de Investigaciones Antropológicas. Facultad de Ciencias Humanas. Universidad de Antofagasta, Antofagasta.

Cruz, P. y J.J. Vacher (eds.) 2008. Mina y Metalurgia en los Andes del Sur desde la Época Prehispánica hasta el Siglo XVIII. Institut de Recherche pour le Développement / Instituto Francés de Estudios Andinos, La Paz.

Darapsky, L. 2003 [1900]. El Departamento de Taltal (Chile), Morfología del Terreno y sus Riquezas. Gobierno de Chile. Consejo Nacional del Libro y la Lectura, Santiago.

Echeverría, H. 2009. El Ferrocarril salitrero de Taltal. Taltalia 2:142-157. Revista del Museo Augusto Capdeville Rojas, Taltal.

Escobar, M. 2008. Informe etnográfico FONDECYT 1080666: Aproximaciones a la historia de la actividad minero-metalúrgica indígena en la costa desértica de la región de Antofagasta: localidades de Taltal y Paposo.

-- - 2009. Informe etnográfico, FONDECYT 1080666: Aproximaciones a la historia de la actividad minero-metalúrgica indígena en la costa desértica de la región de Antofagasta: localidades de Taltal y Paposo.
Espech, R. 1897. El jubileo de Atacama. Estudio sobre la situación económica de esta provincia a través de cincuenta años. Escrito para el Boletín de la Sociedad Nacional de Minería. Imprenta La Gaceta, Prat 19, Santiago.

Espinosa, O. 1980 [1979]. Latorre y la Vocación Marítima de Chile. Impresiones EIRE, Santiago.

Eyzaguirre J. 1994 [1967]. Breve Historia de las Fronteras de Chile. Editorial Universitaria, Santiago.

Eyzaguirre, J. y F. Silva 1966. Nuevos testimonios de la jurisdicción del reino de Chile en el desierto de Atacama. Historia 5:191-195. Instituto de Historia Universidad Católica, Santiago.

Fernández, M. 1987. Formación del Proletariado en el Norte Chileno. Camanchaca 4:15-22.

Flores, J.R. S/F. La minería del Norte. Repaso de la historia de la minería de Chile. Desde sus comienzos hasta época actual. Estudio realizado por Juan Ramón Flores, consejero regional, II Región de Antofagasta, Gobierno de Chile. PDF www.redminera.com. Manuscrito.

Gimeno, H. 2005. Taltal Crisol de Nacionalidades. Historia y Geografía Humana. Editado, auspiciado y distribuido por la Ilustre Municipalidad de Taltal. Impreso en PRINTTEC, Talca.

- - - 2008. Taltal a 150 Años del Sueño de José Antonio Moreno. Editado, auspiciado y distribuido por la Ilustre Municipalidad de Taltal. Impreso en PRINTTEC, Talca.

Gluzman, G. 2007. Minería y metalurgia en la antigua gobernación del Tucumán (siglos XVI-XVII). Memoria Americana. Cuadernos de Etnohistoria 15:157-184. Buenos Aires.

González, S. 2002. Hombres y Mujeres de la Pampa. Segunda edición, LOM Ediciones, Santiago.

González, J. 1992. Rafael Andreu y Guerrero 1760-1804-1819. En Episcologio Chileno 1561-1815, dirigido por C. Oviedo, editado por M. Barrios Valdés, Tomo III, pp. 299-326. Ediciones Universidad Católica de Chile, Santiago.

- - - 2008. La Conquista de una frontera. Mentalidades y tecnologías en las vías de comunicación en el desierto de Atacama. Revista de Geografía Norte Grande 40:23-46.

Grez, S. 2007. Los Anarquistas y el Movimiento Obrero: La Alborada de "La Idea" en Chile, 1803-1915. LOM Ediciones, Santiago.

Haber, A. 2000. La mula y la imaginación en la arqueología de la Puna de Atacama: una mirada indiscreta al paisaje. TAPA 19:7-34. Santiago de Compostela.

Hanisch, W. 1984. La estancia de Paposo y la cuestión de límites. Historia 19:203-218. Instituto de Historia Pontificia Universidad Católica, Santiago.

Herrmann, A. 1900. Estado de la Minería de Cobre en Chile. Imprenta Universo, Santiago.

Latcham, R. 1910. Los Changos de la Costa Norte de Chile. Imprenta Cervantes, Santiago.

Lazo, L. y E. Téllez 1984. Los changos del distrito de Paposo a fines de la colonia: matrícula inédita de habitantes de una población costera. Revista Futuro 7:12-50. Ilustre Municipalidad de Taltal, Taltal. 
Lizárraga, R. 1987 [1594-1608]. Descripción del Perú, Tucumán, Río de la Plata y Chile. Edición de Ignacio Ballesteros, Historia 16, Madrid.

Llagostera, A. 2005. Culturas costeras precolombinas en el norte chileno: secuencia y subsistencia de las poblaciones arcaicas. En Biodiversidad Marina: Valoración, Usos y Perspectivas, editado por E. Figueroa B., pp. 107-148. Editorial Universitaria, Santiago.

Martínez, J.L. 1998. Pueblos del Chañar y el Algarrobo. Los Atacamas en el Siglo XVII. Dirección de Bibliotecas, Archivos y Museos, Santiago.

Matte, J. 1981. Misión en el Paposo. Teología y Vida XXII:51-64.

Melero D. y D. Salazar 2003. Historia colonial de Conchi Viejo y San José del Abra y su relación con la minería en Atacama, norte de Chile. Revista de Historia Indígena 7:55-86. Santiago.

Mellet, J. 1900 [1824]. Viajes por el Interior de la América Meridional, traducido de la edición francesa de 1824, Imprenta i Encuadernación Universitaria, Santiago.

Millán, A. 2004. La Minería Metálica en Chile en el Siglo XIX. Editorial Universitaria, Santiago.

Núñez, L. 1984. Tráfico de Complementariedad de Recursos entre las Tierras Altas y el Pacífico en el Área Centro-Sur Andina. Tesis Doctoral. Departamento de Antropología Cultural, Universidad de Tokio, Japón.

- - - 2006. La orientación minero-metalúrgica de la producción atacameña y sus relaciones fronterizas. En Esferas de Interacción Prehistóricas y Fronteras Nacionales Modernas: los Andes Sur Centrales, editado por H. Lechtman, pp. 205-253. Instituto de Estudios Peruanos e Institute of Andean Research, Lima.

Núñez, L. y J. Varela 1967. Sobre los recursos de agua y el poblamiento prehispánico de la costa del Norte Grande de Chile. Estudios Arqueológicos 3-4:7-41.

Oviedo, C. 1982. Andreu Guerrero, sacerdote misionero. Revista Anales, Facultad de Teología XXXIII:189-205. Santiago.

Palmer, M. 2004. The archaeology of industrialization: Introduction. En The Archaeology of Industrialization, editado por D. Baker y D. Cranstone, pp. 1-4. Maney Publishing, UK.

Philippi, R.A. 1860. Viaje al Desierto de Atacama hecho de orden del gobierno de Chile en el verano de 1853-54. Libreria de Eduardo Antón, Halle en Sajonia.

Sabella, A. 1959. Norte Grande. Editorial Orbe, Santiago.

Said, E. 2002. Orientalismo. Editorial Debate, Madrid.

Salazar, D., V. Castro, J. Michelow, H. Salinas, V. Figueroa y B. Mille 2010. Minería y metalurgia en la costa arreica de la Región de Antofagasta, norte de Chile. Boletín del Museo Chileno de Arte Precolombino 15:9-23.

Salazar, D., V. Castro, H. Salinas y V. Varela 2009. Nuevas investigaciones sobre la prehistoria y la antigua minería de Taltal. Taltalia 2:111-118. Revista del Museo Augusto Capdeville Rojas, Taltal.

Salazar, D., D. Jackson, J.L. Guendon, H. Salinas, D. Morata, V. Figueroa, G. Manríquez y V. Castro 2011. Early evidence (ca.
12,000 BP) for iron oxide mining on the Pacific coast of South America. Current Anthropology 52:463-475.

Salazar, D., D. Melero y C. Jiménez 2005. Los últimos 200 años en Conchi Viejo y San José del Abra (II región): Reflexiones desde la Arqueología histórica y la etnografía. Actas del XVI Congreso Nacional de Arqueología Chilena, pp. 227-237. Sociedad Chilena de Arqueología-Museo Nacional de Historia Natural de Concepción. Escaparate Ediciones, Concepción.

San Francisco, A., B. Ballester, J. Sepúlveda, M. Lasnibat y A. Sepúlveda 2009. Flor de Chile. Vida y salitre en el cantón de Taltal. PM Impresores. Consejo Nacional de la Cultura y las Artes, FONDART, Santiago.

San Francisco, A., J. Sepúlveda y B. Ballester 2010. Arqueología y memoria. Perspectiva histórica de la oficina salitrera Flor de Chile, cantón de Taltal. Taltalia 3:87-95. Museo Augusto Capdeville Rojas, Taltal.

San Román, F. 1894. Reseña industrial e histórica de la minería y metalurgia de Chile. Publicaciones de la Exposición de Minería y Metalurgia de Santiago. Escrita por encargo de la Comisión directiva de la Exposición de Minería y Metalurgia. Santiago de Chile, Imprenta Nacional, Santiago.

- - - - 1896. Desierto y Cordilleras de Atacama. Tomo Segundo. Imprenta Nacional, Santiago.

Sayago, C.M. 1973 [1874]. Historia de Copiapó. Editorial Francisco de Aguirre S.A., Buenos Aires-Santiago.

Solari, E. 1966. La minería prehistórica de Chile. Cuprum 9:10-13.

Thayer, T. 1925. Estancia de Paposo. Informe de don Tomás Thayer Ojeda sobre la interpretación del título primitivo de Estancia. Imprenta y Litografía Balcells y Co., Santiago.

Treutler, P. 1958. Andanzas de un Alemán en Chile 1851-1863. Traducción de Carlos Keller. Editorial del Pacífico S.A., Santiago.

Venegas, H. 2008. El Espejismo de la Plata. Trabajadores y Empresarios Mineros en una Economía en Transición. Atacama 1830-1870. Editorial USACH, Colección Ciencias Sociales, LOM Impresores, Santiago.

Vivar, G. de 1979 [1558]. Crónica y Relación Copiosa y Verdadera de los Reinos de Chile. Edición de L. Sáez-Godoy. Biblioteca Iberoamericana, Berlín.

Weaver, B.J.M. 2008. Ferro Ingenio: An Archaeological and Ethnohistorical view of Labor and Empire in Colonial Porco and Potosí. Thesis for the Degree of Master of Arts. Department of Anthropology, Western Michigan University, Michigan.

Yáñez, N. y R. Molina 2008. La Gran Minería y los Derechos Indígenas en el Norte Grande de Chile. LOM Ediciones, Santiago.

\section{Fuentes inéditas}

1854-1860. Archivo Claudio Gay, vol. 42, foja 159. Manuscrito, Biblioteca Nacional, Santiago. Trascripción de Manuel Escobar, Fondecyt 1080666.

1923. Memoria de la gobernación de Taltal del año 1923. Intendencia de Antofagasta, vol. 24. Manuscrito, Biblioteca Nacional, Santiago. Trascripción de Manuel Escobar, Fondecyt 1080666. 


\section{Notas}

1 Es resultado de FONDECYT 1080666 y FONDECYT 1110196.

2 Los capachos son especies de mochilas, bolsos de cuero con dos tirantes que se cargaban a la espalda para trasladar recursos y bienes, en este caso, mineral. La información etnográfica para la zona costera indica que eran hechos de cuero de vacuno o de lobo marino, lo que expresa vínculos con los conocimientos y prácticas prehispánicas, especialmente respecto a la fabricación de estos bolsos y de balsas inflables del mismo material.
3 El apelativo "chango" aparece en la literatura colonial a partir del siglo XVII, para referirse a la población indígena, no necesariamente monoétnica, que habitaba en las costas del norte de Chile y se dedicaba a la recolección de mariscos y a la pesca (ver Bittmann 1984; Castro 2009:95-104; Latcham 1910:22; entre otros).

4 Dentro de los marcos del Proyecto FONDECYT 1050991.

5 La información etnográfica indica que un caso particular es el de la mina Guanaco, que atrajo gente durante la década de 1960. 
